\title{
Measuring and Modelling Soil Evaporation in an Irrigated Olive Orchard to Improve Water Management
}

\author{
Luca Tezza $^{1}$, Melanie Häusler ${ }^{2}$ D, Nuno Conceição ${ }^{3}$ and Maria Isabel Ferreira ${ }^{3,4, *(D)}$ \\ 1 CIRVE-Centro Interdipartimentale per la Ricerca in Viticoltura ed Enologia, Università di Padova, \\ 31015 Conegliano (TV), Italy; luca.tezza@unipd.it \\ 2 CEF, Centro de Estudos Florestais, Instituto Superior de Agronomia, Universidade de Lisboa, Tapada da \\ Ajuda, 1349-017 Lisboa, Portugal; aa18795@isa.ulisboa.pt \\ 3 LEAF, Linking Landscape, Environment, Agriculture and Food, Instituto Superior de Agronomia, \\ Universidade de Lisboa, Tapada da Ajuda, 1349-017 Lisboa, Portugal; nuconceicao@isa.ulisboa.pt \\ 4 DCEB, Departamento de Ciências e Engenharia de Biossistemas, Instituto Superior de Agronomia, \\ Universidade de Lisboa, Tapada da Ajuda, 1349-017 Lisboa, Portugal \\ * Correspondence: isabelferreira@isa.ulisboa.pt
}

Received: 16 October 2019; Accepted: 27 November 2019; Published: 29 November 2019

\begin{abstract}
The aim of this study was to estimate soil evaporation $(E s)$ in an intensive olive orchard. Measurements of Es were performed for 19 days using microlysimeters, during summers 2010, 2011 and 2012 in southeast Portugal. In order to relate each area type to radiation transmissivity, ground cover measurements were performed over the years. These data were used to calibrate and validate an empirical model for $E s$ estimation. Measured daily average $E s$ was $0.55 \pm 0.14 \mathrm{~mm}$; the model estimated $0.53 \pm 0.18 \mathrm{~mm}$ for the same days, with a determination coefficient of 0.94 . This corresponds to $9 \%$ of the reference evapotranspiration, representing well the overall values estimated for the summer, except for days after rain. Regarding the wet area, measured Es for the validation data set was $2.42 \mathrm{~L} /\left(\mathrm{m}^{2}\right.$ of wet area), the estimated was $2.49 \mathrm{~L} /\left(\mathrm{m}^{2}\right.$ of wet area). Measured average Es in dry area (validation data set) was $0.42 \mathrm{~L} /\left(\mathrm{m}^{2}\right.$ of dry area), estimated $E s$ was $0.43 \mathrm{~L} /\left(\mathrm{m}^{2}\right.$ of dry area). The large exposed dry area had a significant contribution to evaporation. On average, estimated Es during a typical Mediterranean summer was 10\% of reference evapotranspiration, representing 30\% of transpiration and $23 \%$ of evapotranspiration.
\end{abstract}

Keywords: lysimeters; evapotranspiration; irrigation; light interception; transmissivity

\section{Introduction}

In regions where summer water scarcity will not allow intensive agriculture, irrigation is essential to maintain high and constant levels of production. For this reason, there was a significant worldwide expansion of irrigated areas at the end of the 60 s, playing a primary role in increasing food production. Later, in the 80s, the expansion of new irrigated areas slowed down due to several factors, including lower performance and higher costs than expected [1]. Therefore, improvement of agricultural water use efficiency is a key issue to alleviate the pressure on water resources of the ever-expanding world population [2]. In areas, where, for climatic reasons, the agricultural sector consumes more than $80 \%$ of renewable water resources, a $10 \%$ increase in global water use efficiency by the agricultural sector would allow $40 \%$ more water for domestic and industrial use [3].

Improving agriculture water use efficiency requests assessing the crop water requirements, allowing optimization of scheduling strategies that, together with the use of more efficient irrigation 
techniques, result in more water-conservative agriculture. The evaporation estimation is particularly critical in any crop with a large ground area exposed to radiation and turbulence.

Studies about soil evaporation $(E s)$ suggest that total evaporation from wet soil, in the first phase, is determined primarily by the solar energy reaching the soil surface [4-6] and could, therefore, be reduced by shade [7]. In fact, for a wet soil, $E s$ is driven and limited by the energy available at the soil surface, at least until cumulative Es attains the threshold between phase 1 and 2 (U, upper limit of cumulative Es during the first stage, using nomenclature and description in the original publication [5]). After this energy-limited stage, Es switches to a soil-limited rate (or falling rate stage), usually expressed as an empirical function of time [5]. In this second phase, the soil evaporation rate is determined by soil hydraulic properties, being not completely independent from meteorological variables $[4,6,8,9]$.

Soil evaporation can be measured (ground truth data) by applying water balance methods including lysimeters (e.g. [10-12]), chamber methods and also from micro-meteorological methods if applied in a large continuous surface. These methods are expensive and some are very labor and time consuming $[10,13,14]$. Modelling is a common approach to overcome these limitations, by measuring soil evaporation over a short period of time and subsequently using the data to calibrate and validate a model to estimate Es over a larger time frame. There are mechanistic models for which detailed information about system parameters and variables are necessary, for example the Penman-Monteith equation with appropriate conductance of soil surface [15] and its modifications (e.g. [16]) or semi-empirical (or empirical) models [5,8,9]. However, the complexity of the canopy geometry with variable positional shadings along the days and seasons, which overlap with the individual geometry of the wet surfaces, makes it quite difficult to solve. Complex models require input data difficult to obtain in some cases. The semi-empirical models are simpler and consequently of lesser applicability but, after proper calibration and validation, they can provide a robust though only locally valuable estimate, as has been shown in several studies (such as $[13,17,18]$ ).

The aim of this study was to create a site-specific model for estimating Es during three irrigation seasons in an olive orchard in Portugal. To calibrate and validate the model, microlysimeters have been used to carry out in-situ measurements of Es.

This approach allows the user to get $E s$ along the season and for the partition of evapotranspiration $(E T)$ into its components (transpiration, $T r$ and $E s$ ). A locally adjusted Es model also enables the researchers to obtain $\operatorname{Tr}$ as ET-Es, when $E T$ is available, for instance from occasional eddy covariance measurements. These results of $\operatorname{Tr}$ can be compared with sap-flow (sap flux density) measured in the stem of the plants which would correspond to approximately $\operatorname{Tr}$ at daily scale. Sap-flow outputs can be obtained by several techniques, using an analogy between heat and mass transport, for instance using heat as a marker. Very often (e.g. [19]), sap flow outputs have only relative value, due to the simplified assumptions and technical limitations, so the in-situ "calibration" is highly recommended. This strategy has been used to perform the required corrections to the sap flow outputs in order to get long-term reliable $\operatorname{Tr}$ estimates [19]. This operational aim requires daily values of $E s$ along the season.

\section{Materials and Methods}

\subsection{Site Description}

The experimental site was located in the southeast of Portugal, in Alentejo region $\left(38^{\circ} 1.34^{\prime} \mathrm{N}\right.$, $8^{\circ} 10.84^{\prime} \mathrm{W}$ ), situated at $97 \mathrm{~m}$ above sea level. The field was a private olive orchard (Olea europaea 'Arbequina'), established in September 2004 with a spacing of $4.8 \times 7 \mathrm{~m}$ on a total area of 10 ha inserted in a larger olive orchard area of $434 \mathrm{ha}$, with lines oriented $330^{\circ} \mathrm{N}$.

The local climate is temperate of the Mediterranean type, characterized by mild and wet winters, and very hot and dry summers (Csa-Köppen-Geiger classification). For Beja (nearby main meteorological station), the average annual rainfall is about $580 \mathrm{~mm}$, of which $5 \%$ falls in summer (http://www.ipma.pt/pt/oclima/normais.clima/1971-2000/002/). The nearest weather station for air temperature, air humidity, incident radiation, wind speed, and rainfall measurements was located 
in "Herdade do Outeiro", about $12 \mathrm{~km}$ from the experimental site (www.cotr.pt, SAGRA network). Based on this data, reference evapotranspiration $\left(E T_{0}\right)$ was calculated, according to the classical Penman-Monteith equation [15] with grass parameters [20].

The soil was classified as Luvisol [21], type ApBtC, derived from sandy rock with an Ap (0-0.5 m) horizon with loam texture with abundant gravel, a Bt $(0.5-1.3 \mathrm{~m})$ horizon with clay texture with few gravel and an horizon C (1.3-2.3 m) with a sandy-loam texture with some gravel. Apparent soil densities of these three horizons were $1.6 \mathrm{~g} / \mathrm{cm}^{3}, 1.4 \mathrm{~g} / \mathrm{cm}^{3}$ and $1.8 \mathrm{~g} / \mathrm{cm}^{3}$, respectively. A detailed description of the experimental site, soil and field measurements has been given [19], in the context of a larger study.

The orchard was drip irrigated, with the drippers spaced about $0.75 \mathrm{~m}$ and located on the tree rows. Irrigation was applied by the farmer generally during night for a few hours, almost on a daily basis (except on early and late season or in case of failure), from late spring to late summer. On average, irrigation depths were $1.3 \mathrm{~mm} /$ day, $1.4 \mathrm{~mm} /$ day, and $1.7 \mathrm{~mm} /$ day in 2010, 2011 and 2012, respectively, with total irrigation volumes of $159 \mathrm{~mm}, 141 \mathrm{~mm}$ and $226 \mathrm{~mm}$ in the three irrigation seasons. In 2012, the irrigation volume was higher (about $+60 \%$ relative to 2011) to account for lower precipitation during the very dry hydrological year (about $-46 \%$ ). The wet area was estimated as $5.7 \%$ of the total area $\left(1.91 \mathrm{~m}^{2}\right.$ per tree, tree social area corresponding to $\left.33.6 \mathrm{~m}^{2}\right)$.

\subsection{Measurement of Soil Evaporation}

Daamen et al. [22] developed a protocol for the use of microlysimeters (ML) based on field trials determining the minimum dimensions and the time for which the soil sample is representative of the external soil conditions for different soil water contents. The design and use of ML in this study are based on recommendations of the cited authors and this team experience [23-25].

Evaporation measurements were carried out with $10 \mathrm{MLs}$, locally built of polyethylene (PE) tubing, with $0.16 \mathrm{~m}$ internal diameter and $0.12 \mathrm{~m}$ height. Cutting edges have been sharpened to facilitate insertion in the soil. The ML was filled-in by pushing it into the soil up to the full height, every time with a new undisturbed soil monolith taken from a correspondent location. After the complete insertion, the soil around was excavated to insert the bottom (metal plate) and remove the ML. These simple ML were sealed by putting adhesive tape linking the wall and bottom.

However, in order to adequately quantify evaporation from the soil monolith, it is necessary to prevent any loss of weight in the ML that is not caused by evaporation. Consequently, in the case of MLs of wet area, uncontrolled water losses by percolation were avoided by installing an additional PE box at the bottom. This allows the free drainage of the soil monolith, almost as in natural conditions, collecting percolated water in the bottom-box and weighing it together with the ML. The separation between the two parts (monolith and closed drainage chamber) consisted of a fine metal grill allowing drainage. The two parts were linked by adhesive tape sealing the ML.

The ML were cleaned, weighted and inserted into their correspondent location with the undisturbed soil sample (Figure 1a). In order to minimize disturbance and to facilitate recurring MLs removal for weighing during the campaign, additional external PE cylinders were installed in the soil. These outer envelopes remained undisturbed in the soil for the total study period.

At any given measurement time, MLs were removed from the outer envelopes, cleaned, weighed and returned to their respective locations. The soil MLs in the wet area were renewed for every irrigation day, while in dry soil every 2 days, on average. This procedure, normally used on herbaceous row crops [26,27], might cause soil disturbance around the measurement location and could affect evaluation of Es. In row crops, this problem is minimized by filling the MLs with soil cores from areas similar to the measurement point and placing them into the fixed outer envelopes. Soil evaporation was gravimetrically measured, using an electronic scale with $0.1 \mathrm{~g}$ resolution.

Measurements have been carried out during the summer seasons: 4 days of records in 2010 and 2011, respectively, and 11 days in 2012, for a total of 19 days of measurements. 


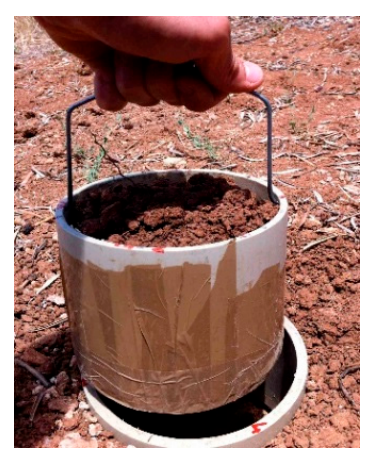

(a)

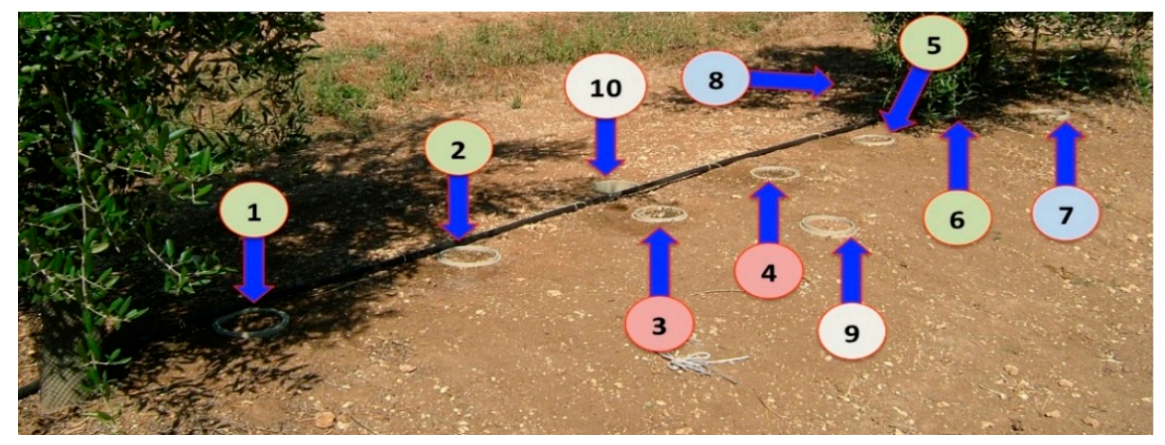

(b)

Figure 1. (a) Microlysimeter ready to be inserted in the external cylinder, where it remains until the next weighting; (b) Microlysimeter positions (numbers refer to Figure 2; dripper tube not centered during measurement time).

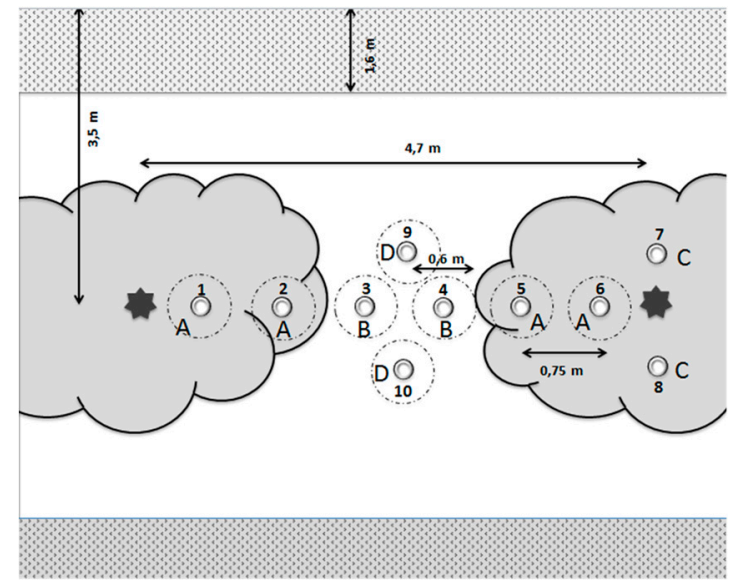

Figure 2. Scheme of microlysimeters position in a tree row with the shade of two contiguous trees: wet shaded area (A, ML 1, 2, 5, and 6), wet sunny area (B, ML 3 and 4), dry shaded area (C, ML 7 and 8), dry sunny area (D, ML 9 and 10). Dashed circles are wet zones (diameter ca. $0.6 \mathrm{~m}$ ). Dotted grey bands are the inter-row spaces. Cornered stars are the trunks of the trees.

The time schedule of Es measurements was half hourly in 2010 and 2011, every 2 hours for 5 days in 2012 and daily (from sunrise to sunset) for all other remaining days.

There were six drippers between two adjacent trees in a row, where each dripper created a wet area with a diameter of $0.6 \pm 0.06 \mathrm{~m}$. We deployed $10 \mathrm{MLs}$ between two trees (Figure 1b): one ML was installed in each wet area, and four MLs in dry soil, placed at the external part of the row. During irrigation, the dripping line was left in the center of the row to keep the soil around the measurement point representative of the wet area. After irrigation, when MLs were positioned, the dripping line was displaced beside the MLs to avoid random input of water in the MLs and to facilitate the operations. The area in the orchard where ML could be practically installed was only on the tree rows or close to it, because of high soil compaction between the rows, caused by heavy agricultural machinery traffic.

Depending on multiple factors, Es variability might be high due to local microclimate characteristics, variability in soil water content and soil properties [7]. Thus, the area projected by the crown was expected to be the low irradiation zone during the day, since it remains in shade at noon, the most important period to discriminate between sunny or shaded soil Es rate [7]. In order to discriminate shaded and sunny areas, the olive trees ground cover $(G C)$, representing the projected canopy area on the ground divided by total area of each plant (social area), was measured (next section, Measurement of Radiation Transmissivity and Ground Cover). 
Each tree social area was split into four areas of the following types: sunny wet, shadow wet, sunny dry, and shadow dry. Four MLs in wet shaded area (A), two in wet sunny (B), two in dry shaded (C) and two in dry sunny area (D) were used (Figures $1 \mathrm{~b}$ and 2). Shadow wet, sunny wet, shadow dry, and sunny dry area were about, $3.6 \%, 2.1 \%, 17.7 \%$, and $76.6 \%$ of the total surface, respectively (areas A, $B, C$, and D, in Figure 2).

\subsection{Measurement of Radiation Transmissivity and Ground Cover}

Over the course of Es measurements, daily photosynthetically active radiation (PAR) curves aside the MLs were measured with PAR sensors (Skye instruments Ltd, Llandrindod Wells, UK), with data being recorded by a data-logger (model CR23X, Campbell Scientific, Logan, Utah, USA). These curves were used to calculate PAR transmissivity $\left(T_{P A R}\right)$, which is defined as the ratio between a reference PAR curve $\left(I_{0}\right.$, recorded in a $100 \% T_{P A R}$ position) and the PAR curve of each ML's position $\left(I_{S}\right)$.

The overhead photograph technique [28] was used to measure GC. At our experimental site, pictures were taken from above the trees to determine the crown projected area (as in [29]), using a camera (Model E450 with Zuiko Digital lens 14-42 mm; 1:3.5-5.6, Olympus, Tokyo, Japan) mounted on a 7.5-m-high stick. Squared metal boards with known areas were used as reference objects. To measure the projected area, photos were processed with an image editing software (ImageJ, https://imagej.net/) that recognized crown perimeter. An increase of apparent size emerges by taking images from a fixed height during the growing season or measuring object at different distances, which can lead to an overestimation of GC. A method was established to calculate the error of apparent size in lettuce growth [30], using the distance formula to compare object with different heights and claiming that a decrease of $1 \%$ in distance results in a $2 \%$ error, while a change in $10 \%$ would result in a $23 \%$ error.

\subsection{Model Description and Validation}

The two-stage Es theory [5] was used, considering wet area in the first stage (energy-limiting stage) and dry area in second stage (falling rate stage). To simulate $E s$ in a wet area, two models were tested. The first uses the equation presented by Bonachela et al. [31]:

$$
E s_{1}=[\Delta /(\Delta+\gamma)] R_{n} a+[\gamma /(\Delta+\gamma)] \operatorname{VPD} 2.7\left(1+u_{2} / 100\right),
$$

where $E s_{1}$ is soil evaporation during the energy-limiting stage $\left(\mathrm{mm} \mathrm{day}^{-1}\right), \Delta$ is the slope of the vapor pressure curve $\left(\mathrm{kPa}^{\circ} \mathrm{C}^{-1}\right), \gamma$ is psychometric constant $\left(\mathrm{kPa}^{\circ} \mathrm{C}^{-1}\right), R_{n}$ is net radiation $\left(\mathrm{mm} \mathrm{day}{ }^{-1}\right)$, $a$ is the PAR transmissivity (calculated as below crown PAR radiation divided by the above crown PAR radiation), VPD is the vapor pressure deficit $(\mathrm{kPa})$, and $u_{2}$ is wind speed at $2 \mathrm{~m}$ height $(\mathrm{km}$ day $^{-1}$ ). Equation (1) is identical to the Penman $E T_{0}$ equation (concerning wind function), except for the parameter $a$ in the radiation term of the equation and for not using the adjustment factor of Doorenbos and Pruitt [32]. However, given the shape of the wet area and its arrangement in a long row, the wind function in Equation (1) $\left(2.7\left(1+u_{2} / 100\right)\right.$ was modified, using the one presented for elongated water bodies [33]:

$$
f\left(u_{2}\right)=\left(2.33+1.65 u_{2}\right) L^{-0.1},
$$

where $u_{2}$ is wind speed at $2 \mathrm{~m}$ height $\left(\mathrm{m} \mathrm{s}^{-1}\right)$, and $L$ is the average width of the water surface. Therefore, combining Equations (1) and (2), the modified equation is:

$$
E s_{1}=[\Delta /(\Delta+\gamma)] R_{n} a+[\gamma /(\Delta+\gamma)] \operatorname{VPD}\left(2.33+1.65 u_{2}\right) L^{-0.1} .
$$

The second model obtains Es from a wet surface under a canopy as follows [9]:

$$
E s_{1}=E T_{0} K_{x}\left(1-\frac{R_{i}}{100}\right)
$$


where $K_{x}$ is a coefficient calculated as a function of $E T_{0}$ rate and wetting frequency (time from last rainfall or irrigation, similarly to Equation (5)) and $\left(1-R_{i} / 100\right)$ is the fraction of daily radiation $\left(R_{i}\right)$ reaching the soil, here assumed equal to PAR transmissivity of Equations (1) and (3).

To estimate $E s$ in a dry area, the falling rate stage equation established by Ritchie [5] was used:

$$
E s_{2}=C\left(t^{0.5}-(t-1)^{0.5}\right),
$$

where $E s_{2}$ is daily soil evaporation during the falling rate stage $\left(m m\right.$ day $\left.^{-1}\right), t$ is time (days) elapsed from the day following rain, and $C$ is a soil parameter $\left(\mathrm{mm} \mathrm{day}^{-0.5}\right)$.

The model performance was verified by testing the linear correlation (coefficient of determination, $r^{2}$ ), the mean absolute error (MAE) between measured and estimated values, and relative coefficient of residual mass (CRM).

As described in Section 3.4 (Model Calibration and Validation), the results analysis showed that another modification in Equation (3) would be still necessary, obtaining Equation (6).

\section{Results and Discussion}

\subsection{Soil Evaporation and Its Relationship with PAR Transmissivity}

Partial tree coverage of the under-tree area resulted in high spatial variability of irradiance at the soil surface (example in Figure 3). When comparing the different patterns observed for $T_{P A R}$ with 2-hourly Es values for a high (ML4, ML10) and low irradiance location (ML1, ML7) beneath the olive crown in wet and dry areas (Figures $3 a$ and $3 b$, respectively), Es follows the course of the $T_{P A R}$ curve over the day. It shows its maximum between midday and 4 p.m. (legal time $=$ solar time $+1: 45$ ), the period with the highest atmospheric demand. During this period, the largest difference between Es rates of sunny and shaded areas occurred, while, at the beginning and end of the day, Es values were similar (Figure 3). Shaded areas had lower values for maximum total daily Es than sunny areas, confirming that $G C$ provides a good indication for the purpose of discriminating high and low Es areas.

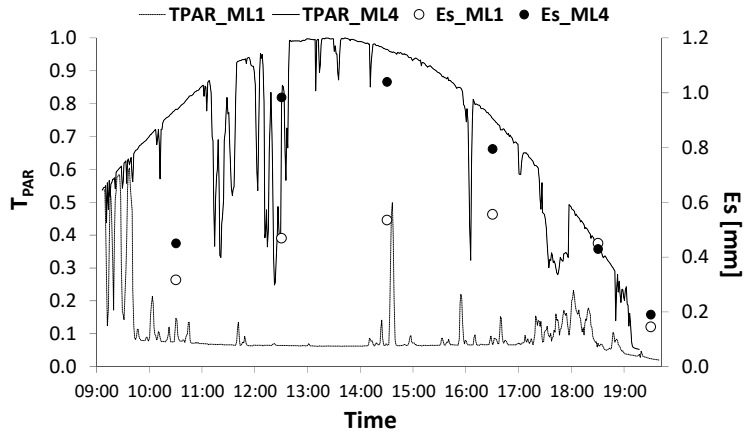

(a)

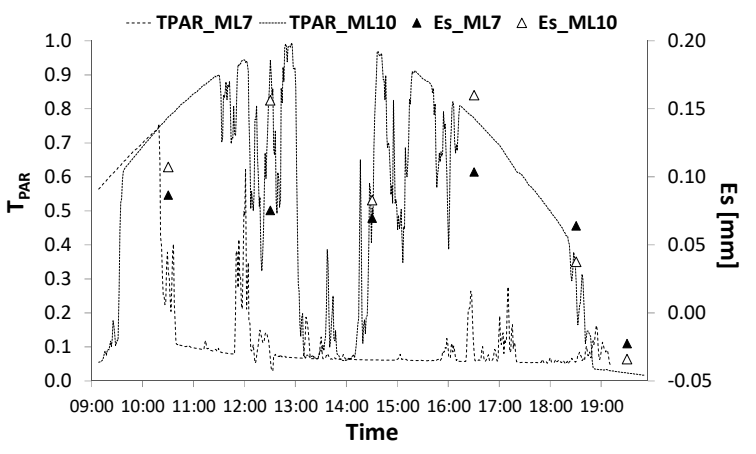

(b)

Figure 3. Daily Es curve (circle for wet area, triangles for dry area; empty symbols for sunny area, filled symbols for shaded area) and $T_{P A R}$ curve (dashed lines) for two wet (a) and two dry (b) MLs, with high

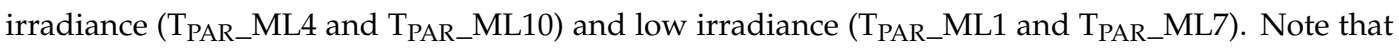
there was condensation (represented in the graph as negative Es) starting in late afternoon for dry MLs (ML7 and ML10). Legal time is shown.

During the energy-limiting stage (wet area), the Es ratio depends strongly on the incoming solar radiation curve, with an apparent slight delay in time (Figure 3a). However, even Es in the dry area did not seem to be completely independent from solar radiation (Figure 3b), showing a decrease in Es with less irradiation and an increase of Es with greater irradiation reaching the soil. This response to incoming energy was not as strong as in the first stage of evaporation, but a slight connection between irradiation and Es ratio is observable. The explanation can rely on the relationship between solar 
radiation and vapor pressure deficit daily courses, as well as, on increasing soil surface temperature impacting sub-surface evaporation; the water vapor flux originated below the surface, becoming the dominant source for this second stage, as suggested by other researchers [34,35].

Wet pairs MLs positioned in the mirror ( 1 and 6, 2 and 5, 3 and 4$)$ had very similar behavior with respect to daily evaporation, suggesting that the division of the areas well reflected Es variability.

A lower irradiance zone was observed within a radius of approximately $0.85 \mathrm{~m}$ from the trunk, with average $T_{P A R}=14 \%$, while a medium irradiance zone was detected down the external part of the crown (from the internal circle to the higher transmissivity zone), with average $T_{P A R}=34 \%$. Thus, the weighted average $T_{P A R}$ for the overall shaded area was $28 \%$. The higher transmissivity zone between two trees in row, outside of the canopy projection on the ground, had an average $T_{P A R}$ of $67 \%$. Calculated average $T_{P A R}$ for wet $(A+B)$ and dry $(C+D)$ areas were $43.3 \%$ and $56.4 \%$, respectively.

On the inter-row dry zone, mainly exposed to the sun, no MLs were installed due to the impenetrability of the hard soil. Transmissivity in this area was expected to be higher compared to the sunny area within (ML 3 and 4) and closer (ML 9 and 10) to the tree rows. However, there were no differences in Es between area $C$ (shaded) and D (sunny), although area D had a double $T_{P A R}$. MLs with high variability of $T_{P A R}$ in dry areas had a difference in $E s$ in the order of tenths of a millimeter. On average, the difference between Es from shaded and sunny dry areas was 6\%, based on a very low value. Therefore, we considered differences in Es fluxes between dry soil close to the row (D) and dry soil inter-row to be negligible, justifying that the results from observations for area $\mathrm{D}$ were extended to the entire area between the rows.

Finally, it should be stressed that night condensation (dew) was observed in C and D areas (represented in Figure $3 \mathrm{~b}$ as negative Es) starting at the end of the afternoon. Consequently, three measurements of night condensation were performed, weighing the MLs at late afternoons and early mornings before the renewal of dry MLs, resulting in an average value of $0.15 \pm 0.06 \mathrm{~mm}$ and $0.25 \pm 0.08 \mathrm{~mm}$, for area C and D, respectively. Agam and Berliner [36], also cited by Shimojima et al. [37], observed that the amount of condensed water in the Negev desert was in the range $0.2-0.3 \mathrm{~mm} / \mathrm{night}$, and thus, the same range was observed here.

\subsection{Ground Cover Measurements}

In 2010, GC was 0.20 (average tree projected area $=5.7 \mathrm{~m}^{2}$ [38]), while the $G C$ average value in 2012 (14 August) was 0.30 (average tree projected area $=8.4 \mathrm{~m}^{2}$ ), resulting in a growth of $48 \%$ in 2 years. Pruning between 2012 and 2013 was particularly intense. New GC measurements were carried out in 2013 (5 July), being 0.22 (average tree projected area $=6.20 \mathrm{~m}^{2}$ ), showing a decrease of $26 \%$ from 2012 to 2013.

\subsection{Average Soil Evaporation from Measurements}

The averaged Es for the areas A, B, C, and D is presented in Figure 4a (A, B, C, and D zones: $3.6 \%$, $2.1 \%, 17.7 \%$, and $76.6 \%$ of total area). The average daily $E s$ for wet and dry areas was respectively $2.41 \pm 0.73 \mathrm{~L} /\left(\mathrm{m}^{2}\right.$ of wet area) and $0.44 \pm 0.12 \mathrm{~L} /\left(\mathrm{m}^{2}\right.$ of dry area), in the following reported as $\mathrm{mm}$ (on wet or dry area basis). Weighted average $E s$ of all areas was $0.54 \pm 0.14 \mathrm{~mm} /$ day.

For the dry area, the average $E s / E T_{0}$ was $0.07 \pm 0.03$. To highlight the difference between $E s$ values of the wet area during irrigation day (day1) and day after (day2), Wallace and Holwill [12] suggested using average daily $E s / E T_{0}$ as an indicator phase swift. Average $E s / E T_{0}$ of wet area on day 1 was $0.49 \pm 0.10$ (i.e., 0.028 on total area basis) and it decreased in day 2 to $0.28 \pm 0.06$ (i.e., 0.016 on total area basis). These values correspond to 0.11 and 0.08 respectively, if $E s$ of the total area is considered. A test carried out, 3 days after irrigation, showed very low differences in Es between MLs, with average $E s / E T_{0}$ of $0.21 \pm 0.01$. Figure $4 \mathrm{~b}$ shows the average daily $E s$ value for dry and wet areas, divided into $E s$ for irrigation day and the day after, for wet areas. The maximum evaporation rate was in the wet area for irrigation day, with clear differences between shaded and sunny wet areas. The subsequent 
day, Es decreased reaching similar values for both sunny and shaded wet areas. Evaporation flux of the shaded wet area was $22 \%$ and $16 \%$ lower than the sunny wet area in day 1 and day2, respectively.

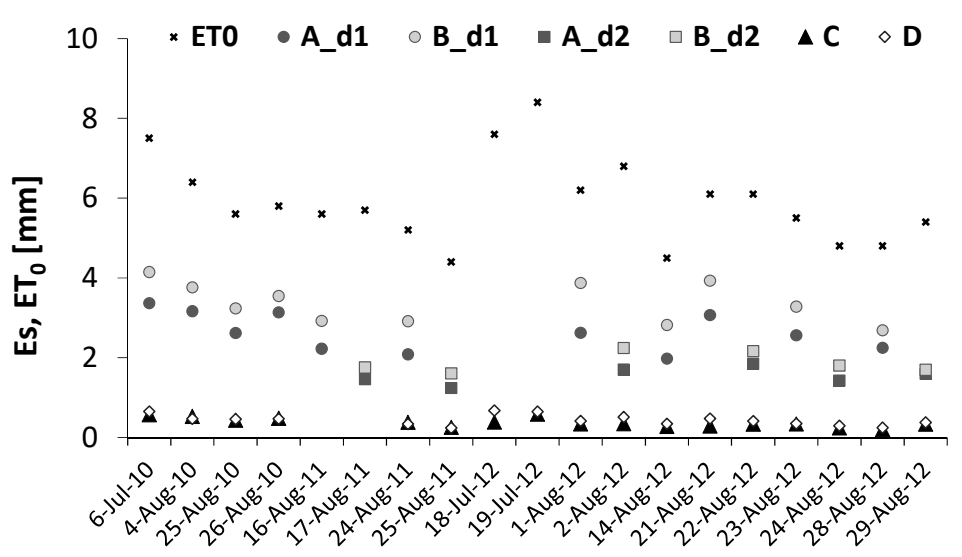

(a)

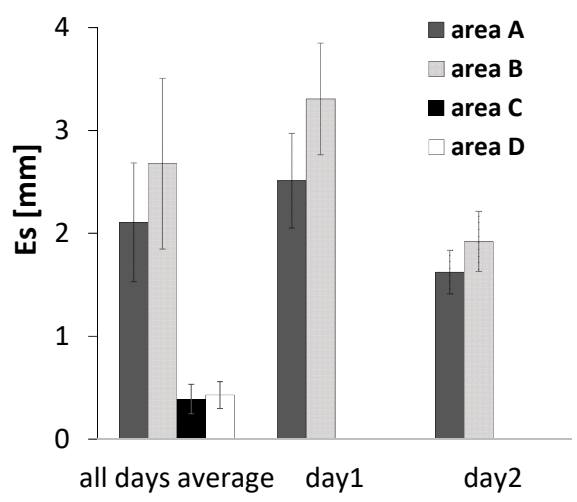

(b)

Figure 4. Daily $E T_{0}(\mathrm{~mm} /$ day) and measured daily $E s(\mathrm{~mm})$ for the wet area (A_d1 and B_d1, d1 is the day of the irrigation event; $A_{-} d 2$ and $B_{-} d 2, d 2$ is the second day after the irrigation event) and dry area (C and D). (a) Daily average Es for the areas A, B, C, and D (all days averaged) as well as average Es for the irrigation day (day1) and for the following day (day2) for wet areas (mm/day) (b). Note that missing data from the wet or dry area were excluded due to poor preparation of the MLs.

A direct relationship between $T_{P A R}$ and Es of wet areas over time was found (Figure 5a). The difference between $E s$ in wet area positions decreased, being more independent from $T_{P A R}$, for the day after irrigation. A good relationship between $E T_{0}$ and $E s$ was found, for both wet and dry areas (Figure 5b), suggesting a dependence of Es during falling rate stage on atmospheric demand, as already stressed.

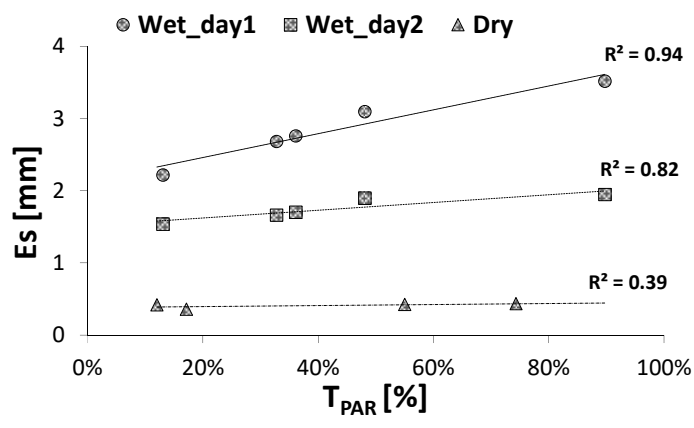

(a)

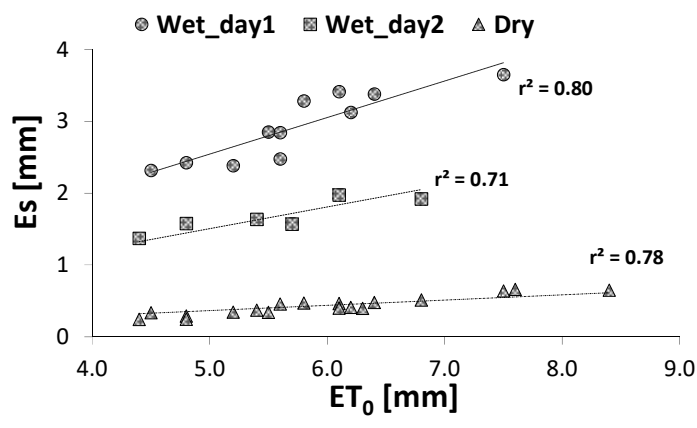

(b)

Figure 5. Relationship between daily Es for the MLs positions in the wet area (irrigation days: Wet_day1; subsequent day: Wet_day2) and dry area (Dry), and (a) daily $T_{P A R}$ (missing ML6) and (b) daily $E T_{0}$.

\subsection{Model Calibration and Validation}

Wet area: In order to check the validity of any necessary adjustments, the dataset was split into two samples, in order to have one dataset for calibration and another dataset for validation of the model. For both calibration and validation of the model, nine points were used for wet and dry areas separately (Figure 6a,b), and eight points for averaged Es (Figure 6c). 
Table 1. Model output evaluation for estimated Es in wet, dry and total area ( $a, b, c$ respectively from left to right in Figure 6). MAE, mean absolute error; CRM, relative coefficient of residual mass; $r^{2}$, coefficient of determination, ${ }^{*}, * * * *$ stand for increasing levels of significance).

\begin{tabular}{|c|c|c|c|c|c|c|c|c|}
\hline $\begin{array}{l}\text { Evaluation } \\
\text { Parameters }\end{array}$ & $\begin{array}{l}\text { Equation (6)_Wet } \\
(\mathrm{a}=0.43 ; \mathrm{b}=0.35)\end{array}$ & $\begin{array}{c}\text { Equation } \\
\text { (4)_Wet }\end{array}$ & $\begin{array}{c}\text { Equation } \\
(3) \_ \text {Wet } \\
(a=0.43)\end{array}$ & $\begin{array}{c}\text { Equation } \\
\text { (6)_Dry } \\
(\mathrm{a}=0.2 ; \mathrm{b}=0.6)\end{array}$ & $\begin{array}{l}\text { Equation } \\
\text { (4)_Dry }\end{array}$ & $\begin{array}{c}\text { Equation (5)_Dry } \\
\text { (C = 7.5 mm } \\
\left.\text { day }^{-0.5}\right)\end{array}$ & $\begin{array}{c}\begin{array}{c}\text { Equation } \\
(6) \_A v g\end{array} \\
(a=0.2 ; b=0.6)\end{array}$ & $\begin{array}{c}\text { Equation } \\
\text { (4)_Avg }\end{array}$ \\
\hline$r^{2}$ & $0.95^{* * *}$ & $0.15^{*}$ & $0.11^{* *}$ & $0.86^{* * *}$ & $0.75^{* *}$ & $0.23 *$ & $0.94^{* * *}$ & $0.78^{* * *}$ \\
\hline Slope & 1.03 & 0.92 & 1.8 & 1.04 & 1.04 & 1.03 & 1.07 & 1.04 \\
\hline CRM (\%) & 2.2 & 0.6 & 96.1 & 5.5 & 2.2 & 15.2 & 5.9 & 02 \\
\hline MAE (mm) & $0.15(6 \%)$ & $0.4(17 \%)$ & $\begin{array}{c}2.12 \\
(86 \%)\end{array}$ & $0.05(12 \%)$ & $\begin{array}{c}0.07 \\
(16 \%)\end{array}$ & $0.08(19 \%)$ & $0.05(10 \%)$ & $\begin{array}{c}0.06 \\
(13 \%)\end{array}$ \\
\hline
\end{tabular}

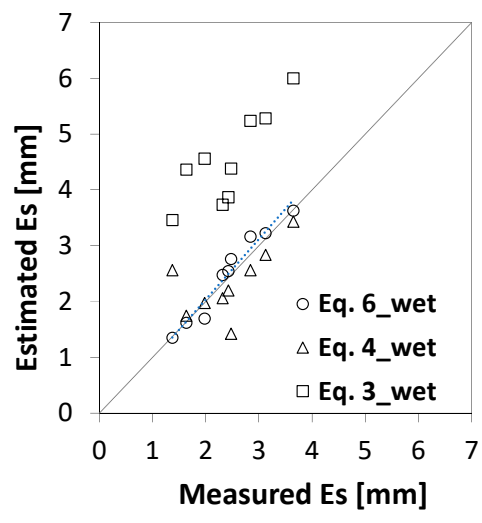

(a)

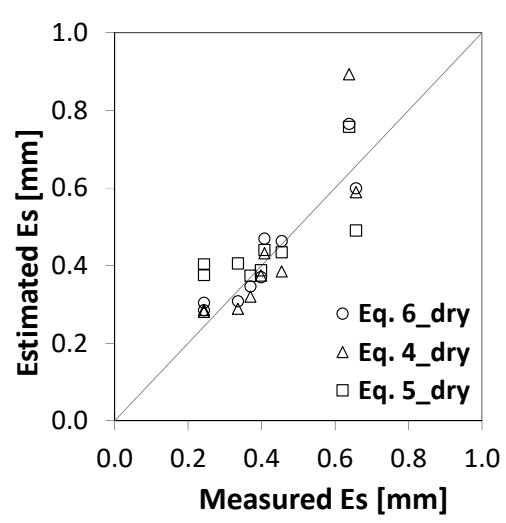

(b)

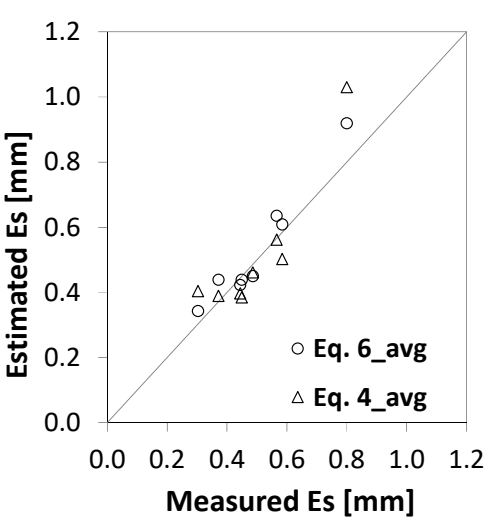

(c)

Figure 6. Measured vs. estimated values of $E s(\mathrm{~mm})$ for wet (a), dry (b) and total area (c), in each case with the parameters shown in Table 1, as before.

Using the original equation (Equation (1), $a=T_{P A R}=0.43$ ), an overestimation (about $85 \%$, MAE about $46 \%$ ) was observed, as expected. However, Equation (3) overestimated $E s$ by about $70 \%$ in day 1 and about $200 \%$ on day 2 , with a determination coefficient of 0.11 (Figure 6a, Table 1). A reasonable estimation was obtained with Equation (4), but with a low regression coefficient (Figure 6a, Table 1). When comparing the results of the aerodynamic term in the Equations (1) and (3) with Es measurements, an overestimation of $29 \%$ and $19 \%$, respectively, was found. One main influencing factor might be the wind speed, which was measured at 2 meters height in open field above grass (standard conditions for meteorological data) not reflecting the wind velocity close to the ground in this rough, highly anisotropic canopy with variable degrees of turbulence below the top of the canopy. To correct the aerodynamic term in Equation (3), a "best fit" approach calibration coefficient named " $b$ " was introduced (Equation (6)).

$$
E s_{1}=\left\{[\Delta /(\Delta+\gamma)] R_{n} a+b[\gamma /(\Delta+\gamma)] D P V\left(2.33+1.65 \mathrm{u}_{2}\right) \mathrm{L}^{-0.1}\right\}\left[t^{0.67}-(t-1)^{0.67}\right] .
$$

Another adjustment was proved necessary. The original Ritchie model [5] could not be applied as a complete soil desiccation cycle was not performed. It was impracticable to determine both values for the parameters of this soil $(U$ and $C$ ) in the equation of the energy-limiting stage proposed by Ritchie [5]. As Es in wet soils is strongly associated with the time elapsed since the last wetting (irrigation or rain), the absence of those ( $U$ and $C$ ) parameters was overcome by adding, in the original equation, a time-dependence function (time since last irrigation, $t$, as in Equation (5)) with a best-fit exponent (obtaining Equation (6)). This was possible because, as mentioned in Section 3.3. (Average Soil Evaporation from Measurements), no clear-cut transition between phase 1 and 2 of evaporation was registered and $E s / E T_{0}$ ratio for wet soil was less than one on irrigation days, decreasing the day after irrigation, suggesting that generally, the irrigation depths (amount of water given per irrigation application) were not enough to bring the bulk soil to field capacity. Most likely the soil already had 
left phase one and continued to be in the transition phase [5,39]. Díaz-Espejo et al. [40] also concluded that after the first day, Es process left phase one, observing a six-fold increase in soil surface resistance between the first and second day.

Considering all these modifications (in summary, Equation (6) results from Equation (3) with $a=T_{P A R}=0.43$ modified with factor $b=0.35$ and a last term similar to Equation (5)), Equations (4) to (6) were compared for the different situations (wet soil, dry soil, and average), with their specific parameters (Figure 6a, Table 1). In the case of the wet area, the best results were achieved with Equation (6).

Dry area: For Equation (5), the best results were achieved using a best fit $C$ parameter of $7.5 \mathrm{~mm} \mathrm{day}^{-0.5}$ (Table 1). Notwithstanding, considering the relationship between dry soil $E s$ and $E T_{0}$, Equations (4) and (6) were also used to estimate $E s$ in dry area, with better results than Equation (5) (Figure 6b, Table 1). However, in this case, the best results with Equation (6) were achieved not using $a=0.56$, that was the average $T_{P A R}$ of dry area, but with factors $a=0.2$ and $b=0.6$.

This result suggests that, when Es was limited by soil hydraulic properties, the aerodynamic term of Equation (6) had a greater influence in determining soil evaporation rates but incident radiation still played a role in driving dry soil evaporation. If analyzing separately the relationship between each term and $E s$, the following values were observed for $r^{2}: 0.93$ and 0.84 for the first (energetic) and second (aerodynamic) terms of Equation (6), in the case of the wet area, and 0.63 and 0.85 in the case of the dry area.

Total area: Es for the total area was estimated using the weighted Es for wet and dry soil calculated with Equations (4) and (6) (Figure 6c, Table 1) with the best results for Equation (6), as expected. For this total Es estimated with Equation (6), the respective parameters for wet and dry areas (Table 1) were used.

A sensitivity analysis was made for the impact of changing values of $a$ and $b$ parameters on $E s$ using Equation (6). A $100 \%$ change on $a$ and $b$ impacts $E s$ in $68.5 \%$ and $31.5 \%$ of its value, respectively, for $a$ and $b$, in the case of the wet area. For the dry area, the corresponding values are $36.7 \%$ and $63.6 \%$, respectively, for $a$ and $b$.

In summary (Table 1), to estimate the $E s$ of the wet area, a determination coefficient of 0.95 and MAE $=0.15 \mathrm{~mm}$ (about $6 \%$ relative error) was found in this study. For the dry area, a lower $r^{2}(0.86)$ and a higher relative error $(12 \%)$ was found. For the total area, the determination coefficient was 0.94 with a MAE of $0.05 \mathrm{~mm}$ (about $10 \%$ relative error). In the literature, also in olive orchards, using Equation (1), other researchers [31,41] reported a MAE of $0.30 \mathrm{~mm}$, with $r^{2}$ of 0.98 for wet areas, and 0.85 for the total area, with higher errors.

\subsection{Model Application at Seasonal Scale}

Equation (6) was used to calculate Es for the entire irrigation period when precipitation events were not frequent (Figure 7). In case of rain, when the entire soil surface was wet, Es was calculated using only the wet area equation (Equation (6), 100\% of Es from wet area). When cumulated Es reached the cumulated value of the precipitation, total evaporation was calculated as the weighted average of wet and dry areas (5.7\% wet area, $94.3 \%$ dry area on average for the 3 years).

Analyzing the results within these 3 years of model application (from 15 July to 15 September for the years 2010, 2011 and 2012), daily average was $0.54 \mathrm{~mm}, 0.84 \mathrm{~mm}$ and $0.59 \mathrm{~mm}$, respectively (Figure 7a).

The cumulated $E T_{0}$ for the month of August for the three years was about $176 \mathrm{~mm}, 155 \mathrm{~mm}$ and $173 \mathrm{~mm}$, respectively; average $E s / E T_{0}$ was $0.10,0.17$ and 0.10 , respectively (Figure $7 \mathrm{~b}$ ). The higher $E S / E T_{0}$, in August 2011, was due to a lower $E T_{0}$ and higher water availability in the soil for the entire orchard. This can be attributed to higher spring precipitation, as well as several cloudy days and unusual precipitations in August. 


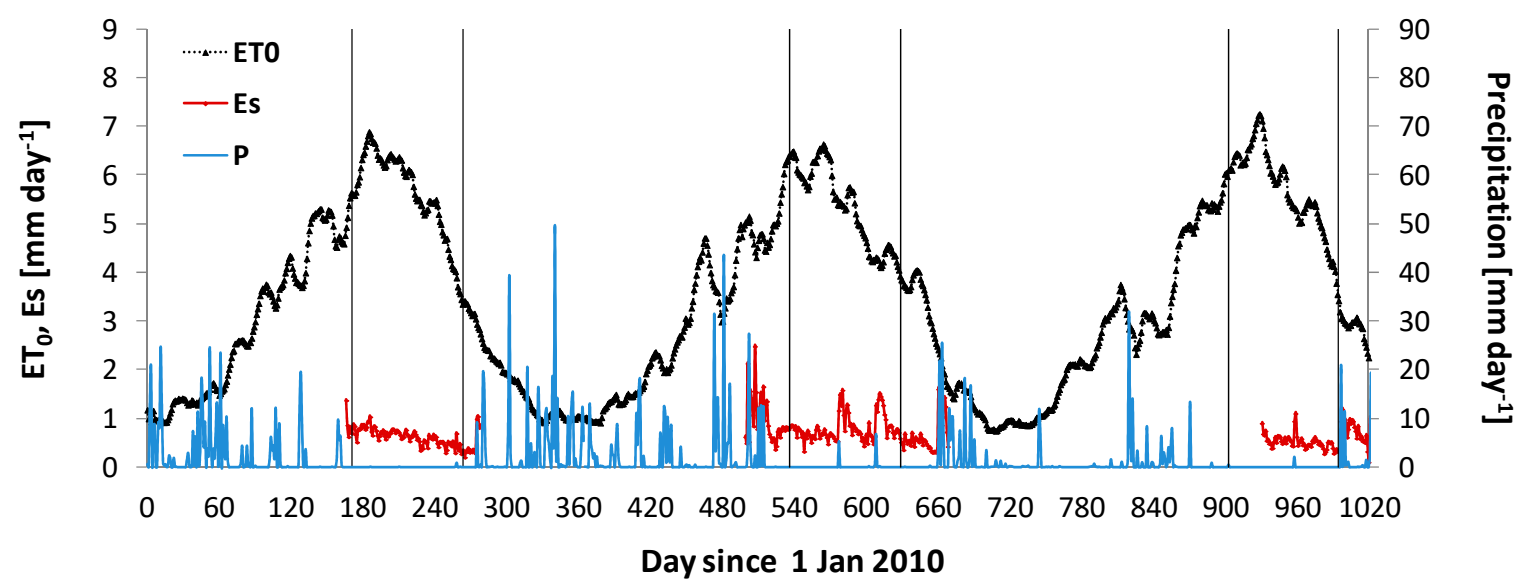

(a)

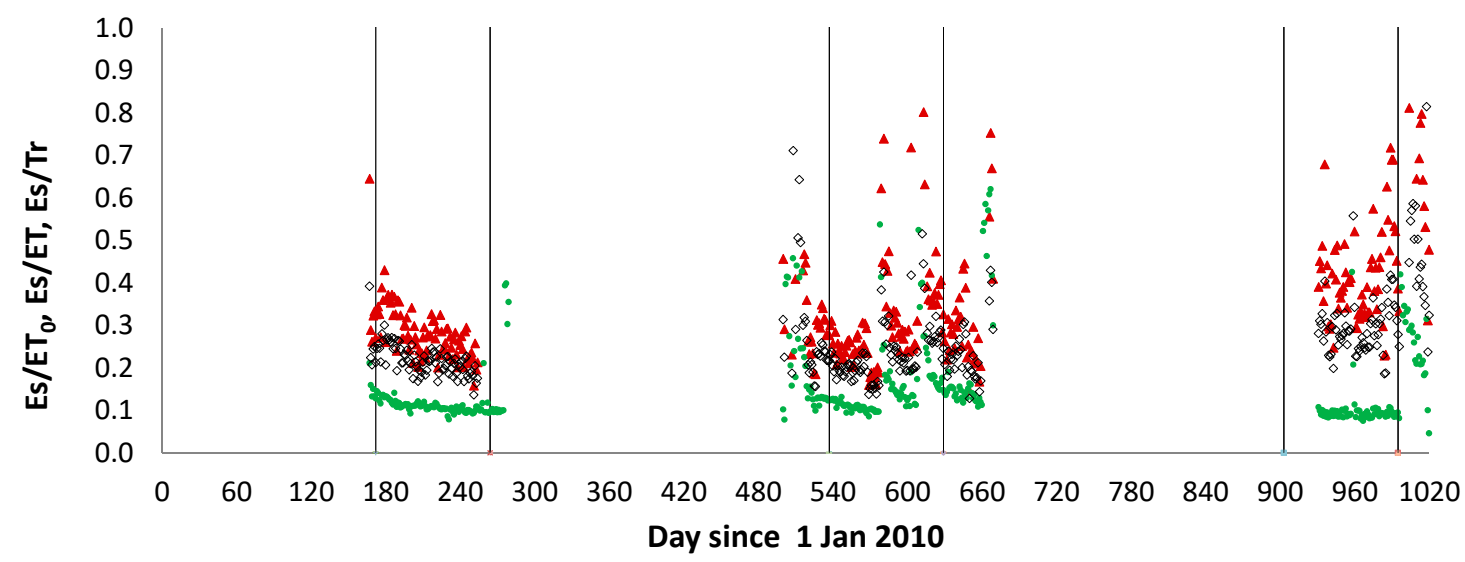

(b)

Figure 7. Seasonal course of (a) Es estimated from model, $E T_{0}$ (running average) and precipitation (P); (b) $E s / E T_{0}$ (points), $E s / E T$ (open diamonds) and $E s / \operatorname{Tr}$ (triangles); data derived from [19]. Vertical bars denote summer limits.

Estimated Es was related to Tr: Es/Tr ranged between ca. 0.4 and 0.2 ( 0.3 on average) during a typical summer such as 2010 with a progressive decrease along the summer, in spite of the permanent dry appearance of the soil surface during the whole of this period and the constant wet area, reflecting the dependence on meteorological conditions, affecting $T r$ with a different dynamic due to phenology. During 2011, higher estimated Es/Tr was obtained, due to occasional precipitation while, during 2012, the higher values can be explained by an exceptional decrease in transpiration by the end of summer [19] due to severe water stress.

Estimated Es was also related to total ET: Es/ET ranged between ca. 0.30 and 0.15 ( 0.23 on average) during summer 2010, with the same dynamics as above, for the other years (Figure $7 \mathrm{~b}$ ).

In a peach orchard under the same climate, also drip irrigated and with a slightly higher ground cover of 0.3 (sandy soil, daily irrigation with wetted area fraction of 0.06), Conceição et al. [42] measured Es from $0.2 \mathrm{~mm} /$ day to $0.6 \mathrm{~mm} /$ day, $E s / E T_{0}$ being between 0.05 and 0.12 , thus in the same range observed here.

For a super-intensive olive orchard ('Arbequina', planted in 2006, spaced $1.35 \times 3.75 \mathrm{~m}$, ground cover of 0.35, same climate), Paço et al. [43] measured Es (8 days during 2011 and 2012). Based on these data, they modeled Es (implementation of Richie model [5]) considering that, from February to early August (2012), 30\% of the soil was covered by mulch resulting from heavy defoliation (frost in February 2012). For 5 months interval, from middle June to late summer, except for rainy days, Es was 
about $1 \mathrm{~mm} /$ day, corresponding to ca. $30 \%$ of $E T$, slightly above the values observed here, as expected (in our study distance between dripper lines is double, so wet area could be much less).

In another olive orchard (Cordoba, Spain, ground cover of $40 \%$, double that in the present study for the typical year of 2010), Villalobos et al. [44] measured ET and Es (eddy covariance method, day of the year 171,172 and 173) when soil surface was dry (although the olive orchard was irrigated) and they concluded that average Es was $0.74 \mathrm{~mm} /$ day (for $E T$ of $3.12 \mathrm{~mm} /$ day), so $E s / E T$ would be on average $24 \%$, in the range estimated in the present study $(0.3$ to $0.15,0.23$ on average).

Even though the wetted area by drippers was only $5.7 \%$ of the total orchard, the model indicates that about $29 \%$ of the evaporated water came from the wetted area in 2010 and 2012, and 19\% in 2011 (rain). During a typical dry summer, $71 \%$ of Es comes from the "dry" area, which is quite a high fraction. Considering the large exposed area, which is apparently extremely dry, and the turbulence generated around the wet area, with the consequent clothesline effect, it could be expected to observe a higher percentage of total evaporation coming from the wet area.

Part of the water evaporated in the exposed dry area could be available through night condensation (as measured in few days) and also eventually, from deeper layers (vapour transfer from below surface), even under severe dryness, which is typically not considered in evaporation modeling of very dry soils but was noticed by others [39,41] as mentioned in Section 3.1 (Soil Evaporation and its Relationship with PAR Transmissivity).

\section{Conclusions}

In irrigation management, Es is often seen as "water loss" to the atmosphere, as it cannot directly be used from the crop and users aim to reduce this component by good practices such as localized irrigation. Thus, a correct estimation of $E s$ is necessary for good irrigation practices. Besides, quantifying Es brings the possibility to check validity of the widely disseminated sap flow techniques when compared to micrometeorological techniques that measure total $E T$, one of the practical aims of this general study.

A total of 19 days of measurements with ML were used to calibrate and validate an empirical model for local Es estimations. The average daily measured Es for wet and dry areas was respectively $2.41 \pm 0.73 \mathrm{~L} /\left(\mathrm{m}^{2}\right.$ of wet area) and $0.44 \pm 0.12 \mathrm{~L} /\left(\mathrm{m}^{2}\right.$ of dry area $)$. Weighted average $E s$ for all areas was $0.54 \pm 0.14 \mathrm{~mm} /$ day.

Best results for Es estimation were achieved with Equation (6) (Table 1), with different calibration factors for dry and wet areas (wet area: $a=0.43$ and $b=0.35$; dry area: $a=0.2$ and $b=0.6$ ). Indeed, we found that the radiation term had higher $r^{2}$ than the aerodynamic term when soil was wetted, while the opposite was found in dry soil. The model overestimated by $6 \%$, with a relative error of $10 \%$ and $r^{2}$ of 0.94 .

For the 3 years of model application (July to September, 2010, 2011 and2012) daily average Es was $0.54 \mathrm{~mm}, 0.84 \mathrm{~mm}$ and $0.59 \mathrm{~mm}$, respectively. During a typical summer such as 2010, Es/Tr ranged between $c a$. 0.4 and 0.2 ( 0.3 on average), Es/ET ranged between ca. 0.3 and 0.15 and average $E s / E T_{0}$ was quite stable around 0.10 (2010).

This study showed that the use of an empirical model for Es estimation provided a robust, locally evaluable estimate, which is useful for evapotranspiration partitioning into its components of evaporation and transpiration with the aim of improved farm water management. Furthermore, the results indicated that a large exposed dry area $(77 \%)$ had a contribution to evaporation above expectations, which is most likely due to the water available from night condensation and more internal layers. Apart from Es quantification and the adsorption effect, once more it could be confirmed that the complexity of the canopy geometry with variable positional shadings along the days and seasons, overlapping with the individual geometry of the wet surfaces and variable turbulence, makes it very difficult to generalize models for evaporation below crowns. 
Author Contributions: Conceptualization, methodology, formal analysis, interpretation, original manuscript preparation: L.T.; coordination, conceptualization, data curation, methodology, interpretation: M.I.F.; collaboration in experimental methodology: N.C.; measurements: L.T., N.C., M.H.; text, review and editing: L.T., N.C., M.H, M.I.F.

Funding: This research was funded by Fundação para a Ciência e Tecnologia (FCT), Portugal supporting the project WUSSIAAME Water Use, Survival Strategies and Impact of Agrochemicals in Agricultural Mediterranean Ecosystems (PTDC/AAC-AMB/100635/2008). Luca Tezza was funded by the Student Mobility for Placement-SMP European Program. Melanie Häusler (PD/BD/52698/2014) and Nuno Conceição (SFRH/BD/66967/2009) were also funded by FCT.

Acknowledgments: The authors are grateful to Carlos Arruda Pacheco for soil classification, to the engineers and students who contributed to this project and to the private land owner (farm Monte do Pardieiro, Agrícola Alentejo, $S A$.) and their workers (Pereira and collaborators).

Conflicts of Interest: The authors declare no conflict of interest.

\section{References}

1. Pereira, L.S. Inter-relationships between irrigation scheduling methods and on-farm irrigation systems. In Proceedings of the ICID/FAO Workshop on Irrigation Scheduling, Rome, Italy, 12-13 September 1995; FAO-Food and Agriculture Organization of the United Nations: Rome, Italy, 1996.

2. Zeggaf, T.A.; Filali, M.Y. Problématique et perspectives de l'efficience d'utilisation de l'eau agricole au Maghreb. In l'Etat des Ressources en Eau au Maghreb en 2009; UNESCO: Paris, France, 2010; pp. $203-217$. ISBN 978-9954-8068-3-0.

3. Lacirignola, C.; Hamdy, A.; Todorovic, M. Regional action program on "water resources management": An overview of actions towards better water use in mediterranean agriculture. In Regional Action Programme (RAP): Water Resources Management and Water Saving in Irrigated Agriculture (WASIA PROJECT); Hamdy, A., Ed.; CIHEAM: Bari, Italy, 2003; pp. 1-18.

4. Philip, J.R. Evaporation, and moisture and heat fields in the soil. J. Meteorol. 1957, 14, 354-366. [CrossRef]

5. Ritchie, J.T. Model for predicting evaporation from a row crop with incomplete cover. Water Resour. Res. 1972, 8, 1204-1213. [CrossRef]

6. Hillel, D. Applications of Soil Physics; Academic Press: Cambridge, MA, USA, 1980; ISBN 0123485800.

7. Kool, D.; Ben-Gal, A.; Agam, N.; Šimůnek, J.; Heitman, J.L.; Sauer, T.J.; Lazarovitch, N. Spatial and diurnal below canopy evaporation in a desert vineyard: Measurements and modeling. Water Resour. Res. 2014, 50, 7035-7049. [CrossRef]

8. Stroosnijder, L. Soil evaporation: Test of a practical approach under semi-arid conditions. Neth. J. Agric. Sci. $1987,35,417-426$.

9. Gallardo, M.; Snyder, R.L.; Schulbach, K.; Jackson, L.E. Crop growth and water use model for lettuce. J. Irrig. Drain. Eng. 1996, 122, 354-358. [CrossRef]

10. Iritz, Z.; Lindroth, A.; Gärdenäs, A. Open ventilated chamber system for measurements of $\mathrm{H}_{2} \mathrm{O}$ and $\mathrm{CO}_{2}$ fluxes from the soil surface. Soil Technol. 1997, 10, 169-184. [CrossRef]

11. Tahiri, A.Z. Evapotranspiration partitioning techniques for improved water use efficiency. In EvapotranspirationFrom Measurements to Agricultural and Environmental Applications; Gerosa, G., Ed.; InTech: Rijeka, Croatia, 2011; p. 410. ISBN 978-953-307-512-9.

12. Wallace, J.S.; Holwill, C.J. Soil evaporation from tiger-bush in south-west Niger. J. Hydrol. 1997, 188, 426-442. [CrossRef]

13. Yunusa, I.; Sedgley, R.; Tennant, D. Evaporation from bare soil in south-western Australia-A test of two models using lysimetry. Aust. J. 1994, 32, 437. [CrossRef]

14. Heusinkveld, B.G.; Berkowicz, S.M.; Jacobs, A.F.G.; Holtslag, A.A.M.; Hillen, W.C.A.M. An automated microlysimeter to study dew formation and evaporation in arid and semiarid regions. J. Hydrometeorol. 2006, 7, 825-832. [CrossRef]

15. Monteith, J.L. Evaporation and environment. In The State and Movement of Water in Living Organisms; Cambridge University Press: Cambridge, UK, 1965; Volume 19, pp. 205-234.

16. Torres, E.A.; Calera, A. Bare soil evaporation under high evaporation demand: A proposed modification to the FAO-56 model. Hydrol. Sci. J. 2010, 55, 303-315. [CrossRef] 
17. Ferreira, M.I.; Valancogne, C.; Daudet, F.-A.; Ameglio, T.; Pacheco, C.A.; Michaelsen, J. Evapotranspiration and crop-water relations in a peach orchard. In Proceedings of the International Conference Evapotranspiration and Irrigation Scheduling, San Antonio, TX, USA, 3-6 November 1996; pp. 61-68.

18. $\mathrm{Xu}, \mathrm{C} . ;$ Singh, V.P. Evaluation and generalization of radiation-based methods for calculating evaporation. Hydrol. Proc. 2000, 14, 339-349. [CrossRef]

19. Conceição, N.; Tezza, L.; Häusler, M.; Lourenço, S.; Pacheco, C.A.; Ferreira, M.I. Three years of monitoring evapotranspiration components and crop and stress coefficients in a deficit irrigated intensive olive orchard. Agric. Water Manag. 2017, 191, 138-152. [CrossRef]

20. Allen, R.R.; Pereira, L.S.; Raes, D.; Smith, M. Crop Evapotranspiration-Guidelines for Computing Crop Water Requirements; FAO Irrigation and Drainage Paper 56; FAO: Rome, Italy, 1998; p. 300.

21. FAO-UNESCO; IUSS Working Group WRB. World Reference Base for Soil Resources, A Framework for International Classification, Correlation and Communication; World Soil Resources Reports n. 103; FAO: Rome, Italy, 2006. [CrossRef]

22. Daamen, C.; Simmonds, L.; Wallace, J.; Laryea, K.; Sivakumar, M. Use of microlysimeters to measure evaporation from sandy soils. Agric. For. Meteorol. 1993, 65, 159-173. [CrossRef]

23. Ferreira, M.I.; Valancogne, C.; Michaelsen, J.; Pacheco, C.A.; Ameglio, T.; Daudet, F.A. Evapotranspiration, water stress indicators and soil water balance in a Prunus persica orchard, in central Portugal. Acta Hortic. 1997, 449, 379-384. [CrossRef]

24. Paço, T.A.; Ferreira, M.I.; Conceição, N. Peach orchard evapotranspiration in a sandy soil: Comparison between eddy covariance measurements and estimates by the FAO 56 approach. Agric. Water Manag. 2006, 85, 305-313. [CrossRef]

25. Ferreira, M.I.; Paço, T.A.; Silvestre, J.; Silva, R.M. Evapotranspiration estimates and water stress indicators for irrigation scheduling in woody plants. In Agricultural Water Management Research Trends; Sorensen, M.L., Ed.; Nova Science Publishers: Hauppauge, NY, USA, 2008; pp. 129-170. ISBN 9781604565799.

26. Boast, C.W.; Robertson, T.M. A "micro-lysimeter" method for determining evaporation from bare soil: Description and laboratory evaluation. Soil Sci. Soc. Am. J. 1982, 46, 689. [CrossRef]

27. Yunusa, I.A.M.; Sedgley, R.H.; Belford, R.K.; Tennant, D. Dynamics of water use in a dry mediterranean environment I. Soil evaporation little affected by presence of plant canopy. Agric. Water Manag. 1993, 24, 205-224. [CrossRef]

28. Adams, J.E.; Arkin, G.F. A light interception method for measuring row crop ground cover. Soil Sci. Soc. Am. J. 1977, 41, 789. [CrossRef]

29. Williams, L.E.; Ayars, J.E. Grapevine water use and the crop coefficient are linear functions of the shaded area measured beneath the canopy. Agric. For. Meteorol. 2005, 132, 201-211. [CrossRef]

30. Klassen, S.P.; Ritchie, G.; Frantz, J.M.; Pinnock, D.; Bugbee, B. Real-time imaging of ground cover: Relationships with radiation capture, canopy photosynthesis, and daily growth rate. In Digital Imaging and Spectral Techniques: Applications to Precision Agriculture and Crop Physiology; American Society of Agronomy: Logan, UT, USA, 2003; Volume 66. [CrossRef]

31. Bonachela, S.; Orgaz, F.; Villalobos, F.J.; Fereres, E. Measurement and simulation of evaporation from soil in olive orchards. Irrig. Sci. 1999, 18, 205-211. [CrossRef]

32. Doorenbos, J.; Pruitt, W.O. Guidelines for Predicting Crop Water Requirements; FAO Irrigation and Drainage Paper 24; FAO: Rome, Italy, 1977; p. 145.

33. McJannet, D.L.; Webster, I.T.; Cook, F.J. An area-dependent wind function for estimating open water evaporation using land-based meteorological data. Environ. Model. Softw. 2012, 31, 76-83. [CrossRef]

34. Han, J.; Lin, J.; Dai, Y. Numerical modeling of soil evaporation process and its stages dividing during a drying cycle. Geofluids 2017, 2017, 1-11. [CrossRef]

35. Gran, M.; Carrera, J.; Olivella, S.; Saaltink, M.W. Modeling evaporation processes in a saline soil from saturation to oven dry conditions. Hydrol. Earth Syst. Sci. 2011, 15, 2077-2089. [CrossRef]

36. Agam, N.N.; Berliner, P.R. Diurnal water content changes in the bare soil of a coastal desert. J. Hydrometeorol. 2004, 5, 922-933. [CrossRef]

37. Shimojima, E.; Tamagawa, I.; Turner, J.V. Experimental investigation of evaporation and condensation in a sandy soil under simulated arid conditions. J. Jpn. Soc. Hydrol. Water Res. 2011, 24, 159-169. [CrossRef]

38. Häusler, M.; Ferreira, M.I.; Conceição, N. Assessment of vegetation parameters in olive trees in the region of Alentejo: A comparison of direct and indirect methods. Acta Hortic. 2014, 1038, 407-414. [CrossRef] 
39. Rosenthal, W.D.; Kanemasu, E.T.; Raney, R.J.; Stone, L.R. Evaluation of an evapotranspiration model for corn. Agronomy 1977, 69, 461-464. [CrossRef]

40. Díaz-Espejo, A.; Fernández, J.E.; Verhoef, A.; Knight, J.R.; Villagarcía, L. The use of high-resolution weighing lysimeters to improve estimates of soil evaporation in drip-irrigated olive orchards. Acta Hortic. 2008, 791, 315-320. [CrossRef]

41. Bonachela, S.; Orgaz, F.; Villalobos, F.J.; Fereres, E. Soil evaporation from drip-irrigated olive orchards. Irrig. Sci. 2001, 20, 65-71. [CrossRef]

42. Conceição, N.; Paço, T.A.; Ferreira, M.I. Medição e estimativa da evaporação do solo em condições de rega localizada. Revista de Ciências Agrárias (SCAP) 2005, 3, 77-92.

43. Paço, T.A.; Pôças, I.; Cunha, M.; Silvestre, J.C.; Santos, F.L.; Paredes, P.; Pereira, L.S. Evapotranspiration and crop coefficients for a super intensive olive orchard. An application of SIMDualKc and METRIC models using ground and satellite observations. J. Hydrol. 2014, 519, 2067-2080. [CrossRef]

44. Villalobos, F.; Orgaz, F.; Testi, L.; Fereres, E. Measurement and modeling of evapotranspiration of olive (Olea europaea L.) orchards. Eur. J. Agron. 2000, 13, 155-163. [CrossRef]

(C) 2019 by the authors. Licensee MDPI, Basel, Switzerland. This article is an open access article distributed under the terms and conditions of the Creative Commons Attribution (CC BY) license (http://creativecommons.org/licenses/by/4.0/). 